\title{
Introduction
}

I will never forget the first time I saw Madame Freedom (1956). I was supposed to be working on a book about contemporary Asian cinema and its relationship to Hollywood and was in the midst of what I expected to be a brief detour into postwar South Korean cinema. I had come across references to Madame Freedom as the most famous Korean film of the 1950 os and had decided it was time to see it for myself. That was how I found myself sitting in front of an old TV in a small, cold, and dusty room deep in the stacks of the Harvard-Yenching Library. I felt a bit out of place. As an American studies scholar, I was unfamiliar with the layout and protocols of this library, which houses the university's Asian studies collection, and I couldn't decipher the titles of the books on the shelves as I walked by. My feelings of out-of-placeness dissipated as I watched the film, however, transformed into what can only be described as joy.

Madame Freedom is a fabulous film. A contemporary melodrama, it tells the story of a middle-class housewife who, after taking a job in a luxury Western goods shop, abandons her domestic duties and begins spending her time in public places of leisure, ultimately entering into an affair with a married man. As I watched, I was captivated by an overwhelming sense of familiarity combined with a curiosity-piquing sense of difference. The film was generically recognizable as a women's picture, and its discontented heroine was kin to the unhappy wives and mothers in Hollywood films such as Beyond the Forest (1949) and The Reckless Moment (1949). It was the film's style, however, that stood out to me. I was struck by director Han Hyung-mo's mastery of classical Hollywood conventions: the confidence of his analytical editing, the boldness of his moving camera, the density of the film's mise-en-scène, and the abundance of its music. At the same time, I recognized 
that a full understanding of the film depended upon a deep familiarity with postwar South Korean life that I did not fully possess. There were nuances of meaning attached to the husband's job as a scholar of the Korean language and to a subplot about smuggling that eluded me. Questions immediately arose in my mind. How was it possible to make such a technically polished film only three years after the end of the Korean War, when the country was still rebuilding? What did it mean to present such an audaciously modern female character in a conservative Confucian society? These questions nagged at me for months. I began watching Han Hyungmo's other films, which also featured modern women navigating contemporary South Korean society. Each of them presented me with a similar combination of familiar and unfamiliar elements, and with each film my fascination grew. Who were these liberated women? And who was the director presenting them in such a sophisticated style? In the end I succumbed to the allure of Han's work and allowed myself to be fully curious about these films. This book is the result of that curiosity.

This book has its origins in a second moment, as well, that occurred while I was reading up on In the Mood for Love (2000), Wong Kar-wai's self-consciously retro melodrama that pays homage to the same postwar period in which Madame Freedom is set. Wong's film, too, features a spectacular style-including glamorous East-West fashions, a restlessly moving camera, and melancholic Nat King Cole songs - that produced in me a similar sensation of insiderness and outsiderness. I came across a quotation from Wong in which he hinted at the historical origins of the film's art design. Referring to Japanese novelist Haruki Murakami, he said, "He and I are about the same age, and we had very similar formative experiences: we were both marked by what I call 'Seventh Fleet Culture' in those years between the Korean War and Vietnam. We both bought the music, the cigarettes, the lifestyle; seeing big foreigners on the streets made a strong impression on us." The Seventh Fleet was a Japan-based US naval unit of some twenty thousand personnel that participated in the Korean War and made thousands of port calls throughout the Pacific region in the 1950 and 1960 s. Wong's words captured my attention because they suggested that the military presence of the United States in Hong Kong, Japan, and Korea during the 1950 os and 1960 os had served as a privileged conduit for an American lifestyle that had a profoundly shaping effect on local tastes in music, fashion, film, and narrative. "Seventh Fleet Culture" gave a name to something I had felt, but couldn't quite identify, as I watched Madame Freedom: the presence in Korea of tens of thousands of American GIs and millions of dollars in US aid, which seemed to be hovering just outside the film's frame and exerting some kind of pressure on what I was seeing inside the frame.

Wong's notion of "Seventh Fleet Culture" joined my fascination with Madame Freedom's style to generate this book's central research questions: Broadly, what is the nature of the relationship between Han's films and the historical moment in which they were produced? More specifically, how are the transnational political, economic, and military forces that we call the Cold War readable in the style of his films? 


\section{HAN HYUNG-MO}

Han Hyung-mo (1917-99) launched the Golden Age of South Korean cinema, a sustained period of cinematic creativity extending from the mid-1950s to the early 1970 in which filmmakers explored their country's experience of modernization from multiple perspectives, as it was happening. Han was the most commercially successful filmmaker of the 1950s, a brilliant innovator who was seen as having his finger on the pulse of South Korean society. As a director, cinematographer, and editor, he was celebrated by his contemporaries as the most modern filmmaker of the day and lauded for introducing new characters, genres, and technologies into Korean cinema. Beginning in 1949, he directed eighteen films, reaching his creative peak between 1954, one year after the Korean War halted, and 1961, when Park Chung-hee seized power in a military coup. Han was deeply interested in women's relationship to modernity, and he foregrounded their experiences and perspectives. He specialized in the making of women's pictures, a genre identified by Steven Chung as "one of the most important and influential of the period's mass cultural products" for their forthright engagement with a rapidly changing society. ${ }^{2}$ Han brought the modern Korean woman to life on screen just as she was emerging as a widespread social reality. The Hand of Destiny (1954) is a noir thriller about a female North Korean spy. Hyperbolae of Youth (1956) is a romantic comedy that contrasts a modern, affluent young woman with a more traditional, less affluent one. The Pure Love (1957) features an airline stewardess, and Men vs. Women (1959) a female obstetrician. Because I Love You (1958) charts the journey of a dancer who embarks on a cultural goodwill mission to Malaya. A Female Boss (1959) is a romantic comedy about the publisher of a women's magazine. My Sister Is a Hussy (1961) charts the comedic drama of a woman bent on avoiding marriage. Han stood out among his peers as a master stylist. At a time when most filmmakers modestly aspired to tell a story via clear images and sounds, Han used film form ostentatiously. His films are masterpieces of commercial art, technically polished and displaying a glamorous aesthetic. For all his commercial success, however, Han has been largely omitted from the canon of major Korean directors, a consequence, perhaps, of both his Hollywood-inflected style and his sympathetic focus on women. ${ }^{3}$

\section{PERIOD STYLE}

Han's style is my object of inquiry: it is what I seek to explain. I approach my quarry from two perspectives. The first is as a "directorial style," which entails identifying its distinctive features and charting how Han deployed them across his oeuvre. A version of auteurism, this approach recognizes that Han possessed a distinctive artistic vision that he was able to sustain for much of his career. My second perspective is to read Han's aesthetic as a "period style," which entails recognizing 
the ways in which it is exemplary rather than exceptional. The concept of period style comes from art history and material culture studies, where it is used to refer to a set of formal conventions that are broadly shared at a given historical moment and that express a more or less coherent set of beliefs. ${ }^{4}$ Han was, in fact, a highly skilled presenter of ideas and creative impulses that were very much alive in the broader South Korean culture. The notion of period style, while not often rigorously applied within film studies, enables one to read film form historically and in relation to other forms of culture. It recognizes that cultural producers are in conversation with each other within and across media, and it invites one to see the extent to which style depends upon the period-specific availability of certain ideas and resources. Reading Han's film through a period style lens requires both a deep historical curiosity and a commitment to formal analysis, which is expressed in the book's organization. Part I consists of three chapters that map the period via political, social, and cultural history; Part II contains four chapters that plumb the intricacies of Han's style via close readings of his films. A brief conclusion marks the end of the period with Park Chung-hee's military coup in 1961 and traces some of its legacies into the New Korean Cinema of the twenty-first century.

This book is a cultural history of Han's style, and as such it asks two questions. First, how is any given element of Han's style used expressively within a film in ways that enhance, complicate, or subvert the meanings produced by the narrative? Taking style seriously means treating it as an independent variable that is not always lashed to the demands of the narrative. This is particularly important with Han's films, which often exhibit a tension between these two registers. Second, how can we read specific elements of style as a form of historical evidence? As Jules Prown has written, "style is inescapably culturally expressive" and the "formal data" embodied in cultural artifacts can be useful for historians willing to tap into nonwritten archives. ${ }^{5}$ When read with a historian's eye, style can provide clues to postwar Korean life that more traditional forms of historical evidence might miss. By reading style in relation to history, I hope to deepen our understanding of both.

Part of this book's mission as a work of cultural history is to call attention to the 1950 s as a distinct phase in Korea's experience of modernization. Prior to the publication of Charles R. Kim's Youth for Nation: Culture and Protest in Cold War South Korea (2017), many social and cultural histories of twentieth-century Korea skipped over the 1950s, jumping straight from the collapse of the Japanese empire in 1945 to Park Chung-hee's coup in $1961 .^{6}$ As John Lie has written, "the 1950 are something of a forgotten decade in South Korea." I am interested in these years as a dynamic period in which postcolonial aspirations, the upheavals of the Korean War, and the waging of the Cold War transformed virtually every aspect of South Korean life. As a phase of modernization, it differs from early-twentieth-century colonial modernity, when Korea's needs were subordinated to those of the imperial center in Japan, and from Park's developmental modernity of the 1960 s and 1970s, when much of social and cultural life was subsumed under the demands of 
export-driven economic growth. Treating Han's style as historical evidence deepens our ability to see the post-Korean War, pre-Park years as what Lie has called an "emancipatory moment" that was "expunged by military rule."

\section{COLD WAR COSMOPOLITANISM}

This book argues that Han's style is an exemplary instance of a period style that I am calling "Cold War cosmopolitanism." Cosmopolitanism is a diffuse term that has been employed in diverse ways by scholars across a range of disciplines. I find it to be a more nuanced and historically grounded term to describe what was happening in the 1950 s than the commonly invoked "fetishization" of America, a psychoanalytic term that implies a kind of collective cognitive error. ${ }^{8} \mathrm{~A}$ cosmopolitan framework invites us to think beyond Americanization and recognize the ongoing legacies of Japanese colonialism and the newly forming relationships with Western Europe, Latin America, and Southeast Asia. I join scholars such as Sheldon Pollock and others who are moving beyond the traditional definition of cosmopolitanism as a universalist political philosophy or ethical commitment and are instead investigating the "range of cosmopolitan practices that have actually existed in history." I am indebted to Mica Nava's articulation of "cosmopolitan modernity," which emphasizes the feminist dimension latent in the revolt against forms of "nationalist traditionalism" that are imbued with restrictive gender ideals. ${ }^{10}$ I owe the term "Cold War cosmopolitanism" to Antoinette Burton, who, in her book on Indian writer Santha Rama Rau, explores how a postcolonial literary sensibility emerged within, and was decisively shaped by, the new US-centered Cold War geopolitical order. ${ }^{11}$

At first glance, Cold War cosmopolitanism seems to be an oxymoron, given that the Cold War entailed dividing the globe into opposing blocs, separating them with iron and bamboo curtains, and pressuring nations to choose exclusive affiliation with one side or the other. The Cold War radically delimited people's engagement with whole regions of the world and constrained their engagement with ideas deemed to be unacceptably Other. In South Korea, violations of this boundary-in the form of expressions of fellow-feeling for communists in North Korea, China, or the Soviet Union-could be punished with imprisonment and death. The Cold War, however, was a force of integration as well as division, and the binding together of the Free World required of its members a new degree of openness towards noncommunist Others. It encouraged South Koreans to look beyond their national borders and understand themselves as connected to other people in Asia and the West. To see the Cold War in terms of integration is to grasp the truth of Foucault's insight that power is productive: it generated new institutions, new relationships, and whole new geographies, such as Free Asia. (I capitalize the ideological phrases Free Asia and Free World, rather than embed them in scare quotes, to distinguish them from actual quotations.) What emerged in South 
Korea in the 1950s, then, was a historically specific form of cosmopolitanism that was contingent upon the Cold War and dependent upon the transnational circuits that it opened up.

Cold War cosmopolitanism is best understood as a cultural formation that emerged alongside the expansion of US power into Asia after World War II. We can define it as a style (a set of textual and aesthetic properties) whose production was stimulated by a body of institutions and practices (a set of material properties) that were launched in accordance with a set of political and social ideas (a set of intellectual properties). It was produced by South Koreans and Americans, working together and apart, who were embarked on a shared project of modernizing a country that had its own culture and history, which included the prior experience of Japanese colonialism. As a cultural formation, Cold War cosmopolitanism had four dimensions. First, it was a political discourse about South Korea's membership in the Free World. It was rooted in the United States-led push, largely supported by Republic of Korea president Syngman Rhee, to secure South Korea's integration into the community of noncommunist, capitalist nations and especially into the emerging entity known as Free Asia. It encouraged the forging of diverse networks of economic, political, and institutional ties with other nations in Asia and the West. Some of these networks were new and others were layered over older, colonial-era ties. As a political discourse, Cold War cosmopolitanism offered a vision of an international community in which South Korea would be a full and equal participantin contrast to its prior status as a subordinate member of the Japanese empire-and the promise of protection from its hostile neighbor to the north.

Second, Cold War cosmopolitanism was an attitude towards modernity. It embraced the project of Western-style modernization optimistically and projected a vision of South Korea moving boldly into the future. It emphasized the opening up of new possibilities and opportunities, and valued exchanges with the world beyond Korea's borders. While it acknowledged the risks modernization posed, it embraced the prospect of wide-ranging social change. It suggested the need to shed the oppressive aspects of Korea's patriarchal Confucianism and replace them with liberal Western values, especially individualism and freedom, which applied to women as well as men. As such, Cold War cosmopolitanism had a feminist dimension. Third, Cold War cosmopolitanism was a material practice of cultural production and dissemination that was linked to Cold War institutions. The enmeshment of South Korea within the Free World created pathways through which resources-capital, technology, advisors, consumer goods, cultural artifacts, ideas, and techniques of cultural production-flowed into Korea. Some of these flows, such as those encouraged by the Asia Foundation, were intentional; others, such as those that originated on US military bases, often were not. Other networks, such as those created by the Asian People's Anti-Communist League and the Asian Film Festival, facilitated the (much smaller) outflow of South Korean people and cultural production into the Free World. As a material practice, then, 
Cold War cosmopolitanism entailed the use of these resources and networks by South Koreans to produce and disseminate their own works of culture.

Finally, Cold War cosmopolitanism was a cultural style, a textual feature manifest in South Korean films, magazines, fashion, performance, advertising, and home design. Aesthetically, this style entailed the appropriation and indigenization of a range of stylistic elements derived from Western models. These elements included material objects such as consumer goods, conventions of representation such as genres, and depictions of social practices such as commercial leisure activities. Cold War cosmopolitan style made a claim for Korea's coevalness with the modern West: by demonstrating familiarity with Western cultural trends, it signaled a rejection of Korea's colonial-era status as "traditional" and "backward" and asserted that Korea occupied the same cultural time as other modern noncommunist countries. Ideologically, it was a distinctly Free Asian aesthetic, showcasing the lifestyles that capitalist democracy promised to make possible.

Cold War cosmopolitanism should be understood as the Asian counterpart to America's Cold War Orientalism, both of which functioned as cultural expressions of the ideal of US-Asian integration. Koreans' embrace of certain elements of Western culture mirrored Americans' simultaneous fascination with Asia. Washington, as part of its push for Free World integration, encouraged Asians and Americans alike to turn their attention to the noncommunist world beyond their borders and to engage with each other. In the United States, this led to the proliferation of middlebrow narratives about Americans forging sympathetic bonds with Asian people through narratives of travel, adoption, medical missionary work, and dance. Cold War Cosmopolitanism explores how this encouragement of Free World engagement affected the content and style of South Korean culture as well, and it is thus something of a sequel to my previous book, Cold War Orientalism. Both are examinations of Cold War liberalism as it found expression in the cultural realm. Sometimes the same institution was intervening in Asian and American culture industries simultaneously, as when the Asia Foundation urged Hollywood producers to make less racist films about Asia at the same time that it was helping anticommunist Asian filmmakers make better-quality films. As Washington encouraged American middlebrow intellectuals to generate sympathetic understandings of Asian peoples, it provided resources for their Korean counterparts to produce works of culture that encouraged sympathetic understandings of American values. At a historical moment when the negative dialectic of anticommunism was omnipresent, both Cold War Orientalism and Cold War cosmopolitanism offered something positive to Americans and Koreans: a way for them to understand themselves as active members in a larger world defined by its "freedom" and as participants in pressing debates about modernity. What we see, then, is that Washington's foreign policies of Free World integration exerted pressures that shaped the cultural fields of both the United States and South Korea in the 1950 s, albeit in very different ways. ${ }^{12}$ 
The 1950s-6os saw the blossoming of diverse cosmopolitan aesthetics across the globe, as cultural producers began imagining into existence new communities and identities. What I am calling Cold War cosmopolitanism was not unique to South Korea or to film, but rather a diversely manifesting style crafted by a broad array of cultural producers, from "free Mandarin" filmmakers in Hong Kong who embraced Americanized visions of capitalist modernity, to editors of highbrow literary journals published around the world and secretly funded by the US government. Its antitheses could be found in the "socialist cosmopolitanism" promulgated within mainland China's literary culture, which encouraged the circulation of texts and authors within communist countries, and in the conventions of a socially critical neorealism, generated in Italy and embraced by filmmakers around the world (including some in South Korea). Cosmopolitan modes of production and consumption likewise flourished among those trying to find a Third Way between capitalism and socialism-from a Buddhist leader-turned-screenwriter in Ceylon to writers, dancers, and filmmakers in Indonesia-as well as those seeking to bypass Cold War frameworks altogether, such as black South African musicians who looked to Hollywood and Harlem to assert a modern urban identity against apartheid's tribalizing logic. Around the world, cosmopolitanism was embraced as a defining feature of modernity and an essential dimension of postcolonial nationhood, one that conveyed an attitude of promise and possibility towards the future. Throughout, cultural production was characterized by what Jennifer Lindsay calls a "magpie-like" process of "taking and shaping" from diverse places and times. ${ }^{13}$

\section{METHODOLOGY}

In keeping with my American studies training, I am employing an interdisciplinary methodology that brings together the microanalysis of individual films with the macrohistory of the Cold War in Northeast Asia. One can think of these as two endpoints of an analytical continuum that ranges from the symbolic at one end to the material on the other. In between are numerous points of connections that bridge the gap between them. My analysis is built upon a wide range of English-, Korean-, and Chinese-language sources (the latter two accessed via translators), archival as well as textual. My core texts are the films directed by Han Hyung-mo, with secondary attention devoted to select films by Ozu Yasujiro of Japan, Shin Sang-ok, and other Golden Age directors. I use the biographies of cultural producers to root these artifacts in their historical moment. I open up to the broader field of public culture by reading Han's cinematic style in relation to the popular women's magazine Yŏwŏn and the best-selling novel on which Madame Freedom was based, as well as to the lives and works of several female public intellectuals, including Korea's first female university president, first female lawyer, and first female fashion designer. Institutions matter in this analysis, and I explore how US military bases and the Asia Foundation functioned as "ports of entry" that 
funneled resources into the hands of individual artists and into culture industries such as publishing and film production. Korean initiatives figure here as well, including Rhee's efforts to define Free Asia on his own terms and to make Korean culture better known within it. Broadening out still further, I delve into economic history to understand the flow of consumer goods and foreign films into Korea, through legal trading relationships and the illegal black market. The chapters that follow move back and forth along this continuum, illuminating connections among individuals, texts, institutions, economic practices, and foreign policy initiatives.

\section{SCHOLARLY CONVERSATIONS}

These chapters participate in several scholarly conversations, in addition to the one on global cosmopolitanisms. This first is among English-language scholars of Korea's Golden Age cinema. While this conversation has not engaged Han's work beyond Madame Freedom in much depth ${ }^{14}$ and has devoted more attention to male-centered melodramas than to women's pictures, ${ }^{15}$ it is rich in transnational analyses ${ }^{16}$ and has begun plumbing the work of individual directors in depth. ${ }^{17}$ A second conversation is taking place among scholars of the cultural Cold War in Asia. They are revealing the nature and extent of Washington's and Beijing's interventions in Asia's cultural life, ${ }^{18}$ piecing together institutional histories of transnational phenomena such as the Asian Film Festival, ${ }^{19}$ and illuminating the impact on women of Cold War ideologies and practices. ${ }^{20} \mathrm{~A}$ third conversation is among scholars of transnational American and other national/area studies who are exploring the creative bursts that took place in popular cultures around the world after World War II, as increased flows of American people, ideas, and cultural forms intersected with local traditions. ${ }^{21}$ Extending the insights that Arjun Appadurai developed in Modernity at Large, they are exploring how the global flows of Americana contributed resources for self- and nation making rather than serving exclusively as instruments of US hegemony. ${ }^{22}$ Limited resources make it impossible for me to engage fully with the scholarly conversations taking place in Korean and other languages.

Cold War Cosmopolitanism explores what happened when transnational flows of resources, people, and ideas intersected with a local culture at a specific historical moment. It charts the pathways through which these flows were channeled, and identifies the institutions that enabled cultural producers to tap into them productively. It interprets the works of cinematic art that ambitious, creative individuals produced as they took advantage of these resources and used them to interrogate the modernity that was taking shape around them. To read Cold War cosmopolitanism as a cultural formation is to understand how deeply style is intertwined with 
the larger forces of history. It is to grapple with Robert Palmer's rhetorical query about the blues: "How much history can be transmitted by pressure on a guitar string?" My hope is that when readers watch Han's films and admire his sweeping camera movements, rich mise-en-scène, and globally sourced soundtracks, they will be able to discern what Carlo Rotella has called "the shaping flows of history" at work beneath the surface of his polished style. ${ }^{23}$ 